\title{
Influence of content of methane in biogas on emission of toxic substances in diesel engine supplied with bifuel
}

\author{
Michał Śmieja, Sławomir Wierzbicki \\ University of Warmia and Mazury in Olsztyn, Faculty of Technical Sciences, ul. Stoneczna 46A, 10-710 Olsztyn, Poland
}

\begin{abstract}
Reduction of toxic compound emissions to the atmosphere is currently the main operating criterion for combustion engines. One possible method for lowering the emissions by combustion engines involves using biogas as an alternative fuel. Biogas can be obtained from different raw materials using different technologies. Therefore, the content of methane, the main combustible biogas component, varies widely.

Biogas can be used as fuel directly for feeding spark-ignition engines. Biogas use is more difficult for compression-ignition engines because of the quite high methane auto-ignition temperature. Therefore, the use of biogas as fuel for compression-ignition engines requires the injection of a small liquid fuel charge into the combustion chamber, whose aim is to cause the ignition of the produced air/biogas mixture.

This paper presents the preliminary results of a study on toxic compound emissions by a dual-fuel compression ignition engine with the main fuel charge fed as biogas.
\end{abstract}

Keywords: CI engine; biogas; methane; toxic emission.

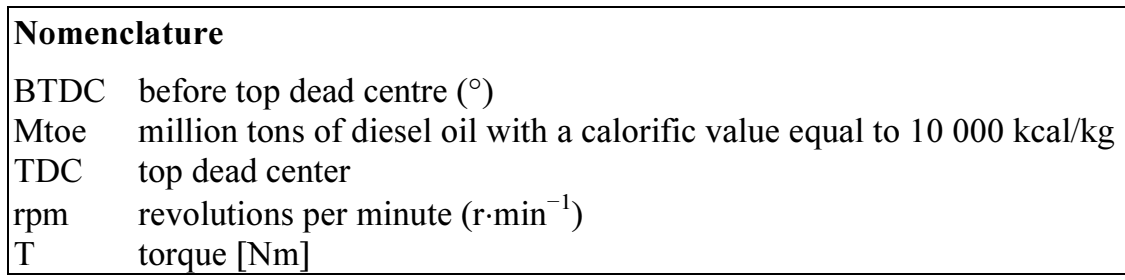

\section{Introduction}

One of the most important problems now facing mankind is the problem of the search for new, alternative energy sources. This is connected with the dwindling resources of fossil fuels, particularly petroleum, as well as growing concern for the natural environment and the fight against global warming $[4,5,6,7]$.

Intensive work on the development of new technologies for energy production from different kinds of renewable sources is currently being carried out around the world. Biogas is one of the fuels which can be a potential energy sources [1,7].

Biogas can be not only obtained from different raw materials and using different technologies, but also in many cases appears spontaneously as a result of chemical processes, e.g. landfill gas. The main combustible biogas component is methane (CH4), biogas also contains substantial amounts of carbon dioxide. Additionally, depending on the origin of biogas, hydrogen and nitrogen can occur, but their levels do not exceed several percent. It is worth noting that methane released spontaneously from different kinds of processes is over 20 times more harmful to the ozone layer than carbon dioxide.

The estimated production of biogas in EU countries was 8.3 Mtoe in 2009 [8, 10]. According to [8, 10], the biogas production potential in 2020 is estimated at around 166 Mtoe. Therefore, biogas should be treated as a potentially significant energy source in the nearest future.

Corresponding author: Michał Śmieja. E-mail address: smieja@uwm.edu.pl

http://dx.doi.org/10.3846/enviro.2014.054

(C) 2014 The Authors. Published by VGTU Press. This is an open-access article distributed under the terms of the Creative Commons Attribution License, which permits unrestricted use, distribution, and reproduction in any medium, provided the original author and source are credited. 
Because biogas can be obtained using different production technologies, its composition is not constant. The percentage of methane in biogas depends on the technology for obtaining biogas and ranges from $35 \%$ to around $75 \%$. It is also worth noting that in some countries, e.g. Sweden, it is possible to carry off purified biogas, the so-called biomethane (with an over 90\% CH4 content), to the gas grid, which enables easy and cheap long-distance transmission of this fuel [1, 4, 5, 6].

One possible way of using biogas is its application as fuel for combustion engines. Currently, both methane and biogas are used mainly as fuel for spark-ignition engines. This is connected with a quite high octane number, which enables engines with a relatively high compression ratio to be used. Unfortunately, spark-ignition engines are much less efficient than compression-ignition engines.

\section{Biogas as fuel for compression-ignition engines}

Compression-ignition engines are currently increasingly displacing spark-ignition engines. CI engines are now the basic drive source not only for trucks and all kinds of machinery, but are also increasingly encountered in cars as well as cogeneration systems. Therefore, replacement of the widely-used SI engines with CI engines in agricultural biogas plants allows higher efficiencies of the whole system to be obtained.

Despite their relatively high efficiency, compression-ignition engines cannot be fuelled with methane or biogas alone due to methane's high auto-ignition temperature (over $920 \mathrm{~K}$ ) [6]. Such a high temperature cannot be obtained by air compression in the combustion chamber of current compression-ignition engines. To initiate an ignition of this mixture in such engines, it is necessary to use an additional ignition source.

One of the best-known methods for air/biogas mixture ignition in CI engines is the injection of a small liquid fuel charge into the combustion chamber, which auto-ignites. This results in gaseous fuel ignition. In such solutions, it is necessary to use a dual-fuel system. Both diesel fuel and all kinds of alternative liquid fuels, including plant and animal fat esters, can be used as a fuel to initiate the ignition of the air/gas mixture [1, 3, 4, 5]. The size of the charge initiating auto-ignition ranges from several to around a dozen percent. It depends on the engine size, with limitations resulting from the used injection system. An example of such a limitation is the overheating of spray nozzles due to the low flow of liquid fuel, which simultaneously serves as a coolant.

Many research facilities are currently conducting studies on the use of gaseous fuels to feed compression-ignition engines. These studies are primarily conducted to determine the minimum liquid fuel charge and its injection parameters including, most importantly, injection pressure and its injection advance angle with respect to TDC, depending on the biogas methane content.

The results for fuelling CI engines with biogas and methane available in the literature confirm the possibility of using these fuels as the main fuels for their feeding $[1,4,5,6]$. As a rule, a decrease in engine power by around a dozen percent is recorded when engines are fed with gaseous fuels, which results from the much higher gaseous fuel volume compared to liquid fuel, causing a considerable decrease in the suckable air volume.

The many studies conducted on feeding engines with gaseous fuels, including biogas, have demonstrated that the exhaust gas smoke levels are lower. This is associated with better mixing and atomization of gaseous fuel compared to the stream of injected liquid fuel. Because of the higher methane combustion temperature than for liquid fuels, such fuelling produces NOx and hydrocarbon emissions also rise slightly. Therefore, additional systems reducing the emissions of these compounds into the atmosphere are used in such solutions. As opposed to feeding CI engines with classical fuels, controlling the course of the combustion process is much more difficult. The widely-used Common Rail systems allow flexible shaping of pressure changes in the combustion chamber when liquid fuels are used by the division of the injected charge into several portions. It should also be noted that controlling the course of the combustion process in such engine fuelling solutions is more difficult as opposed to modern common rail liquid fuel engine systems. Because the whole fuel volume is fed to the combustion chamber in one portion, the division of the charge as for liquid fuels is not possible. The course of this process depends, in this case, only on the load concentration in the combustion chamber and on its temperature. Two-way injectors enabling direct injection into the combustion chamber of both liquid and gaseous fuel have currently already been developed and such a solution enables controlling the gaseous fuel feeding process and, therefore, the course of combustion. Such solutions a currently used only in large engines.

One of the main problems related to engine dual-fuelling is the need to use large tanks for compressed gaseous fuel. This problem is of primary significance for fuelling engines powering vehicles and mobile machines. In engines working under stationary conditions, e.g. in biogas plants, this problem is negligible.

\section{Test stand}

Most of the works concerned suppplying CI engines with methane is realised with previous generation engines equipped with mechanical injection system. This kind of injection based on mechanical solutions is difficult to flexible setting such parameters like: angle of injection, fuel dose, injection pressure. The optimalisation of utilizing energy causes the spreading injection equipment based on the system Commo Rail. It makes possible increase the energetic efificiency of modern engines and minimizes its negative impact on natural environment [4, 9].

Conception of the signal flow in the test stand is presented in Fig. 1. 


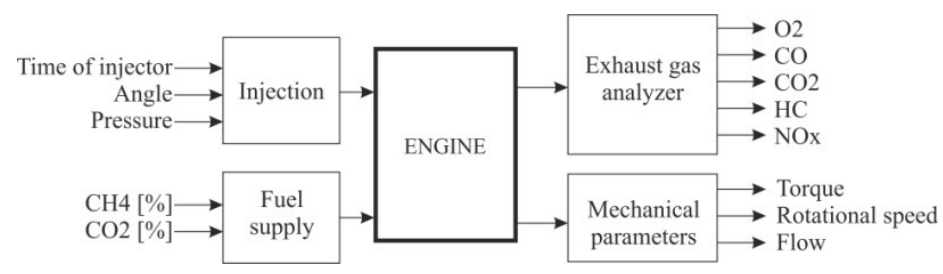

Fig. 1. Signal flow in the test stand

To determine the effect of supplying Ci engines with bio-gas, there construction of a test stand based on AM211 brake was. The experiment was conducted with a Yanmar air-cooled single-cylinder compression-ignition engine (Table 1).

To direct acces to such parameters like: angle of injection, fuel dose, injection pressure the original mechanical injection system was replaced with the autonomous CR system. The scheduled in the experiment settings of the injection process comes from the central stand controller as depicted in Fig. 2.

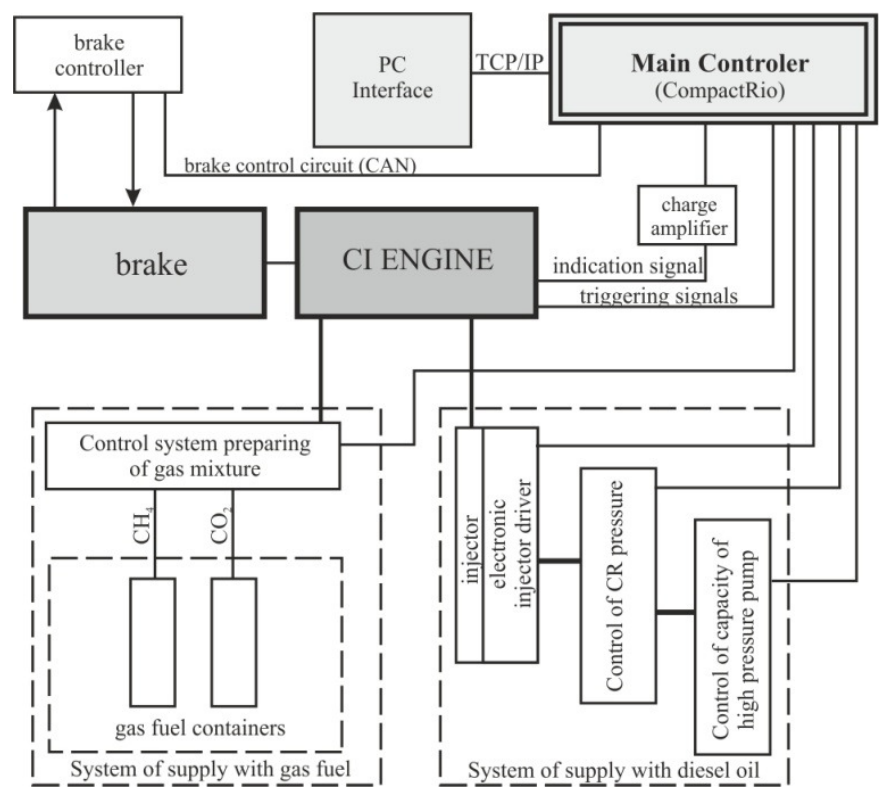

Fig. 2. Scheme of test stand

Table 1. Basic technical parameters of the engine YANMAR L100N6

\begin{tabular}{ll}
\hline Parameter & Value \\
\hline Engine capacity & $534 \mathrm{~cm} 3$ \\
Compression & 20 \\
Bore / stroke & $86 / 75 \mathrm{~mm}$ \\
Max. power & $7,4 \mathrm{~kW}$ \\
Max. torque & $27 \mathrm{Nm}$ \\
Max. rotation speed & $3600 \mathrm{rpm}$ \\
Type of injection & direct injection \\
Cooling system & air \\
\hline
\end{tabular}

Due to the floating parameters of gas-mixture derived from real sources of bio-gas as well as yield a repetable results a special laboratory system was prepared to manage to flamable gas-mixture.

The diagram of the gaseous mixture preparation system is shown in Figure 3.

Mass flow controllers were used in this system with the following parameters are presented in Table 2. 


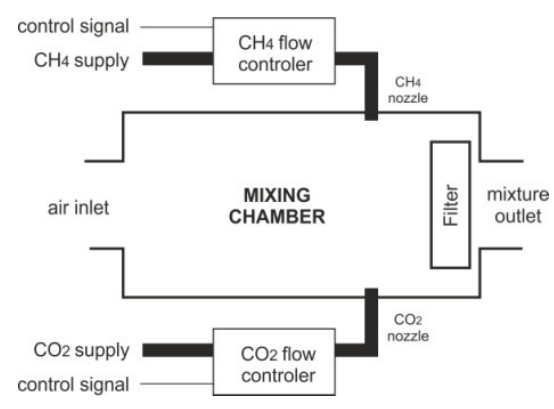

Fig. 3. System of preparing of gas mixture

Table 2. Parameters of mass flow controlers

\begin{tabular}{lll}
\hline Parameter & CH4 & CO2 \\
\hline Type & D-6361 DR & SLA5851SB1BC1B2A1 \\
Flow rate & $0-130 \mathrm{ln} / \mathrm{min}$ & $0-75 \mathrm{ln} / \mathrm{min}$ \\
Inlet pressure & $2.5 \mathrm{bar}$ & $1.5 \mathrm{bar}$ \\
Outlet pressure & $0 \mathrm{bar}$ & $0 \mathrm{bar}$ \\
Input/output singal & $0-10 \mathrm{~V}$ & $0-5 \mathrm{~V}$ \\
Communication interface & RS 232 & RS 485 \\
\hline
\end{tabular}

\section{Preliminary tests}

Conducting targeted research on supply Diesel engines biogas requires a preliminary study which aim was to revise a work of individual systems and subassemblies as well as correctness of operation of the measuring apparatus. Thuse far, the researches were designed to determine the effect of methane power diesel engine. The experiment was conducted with nitrified natural gas. The methane percentage was approximately $96 \%$. The results were compared to the results used for supplying the engine with a commercially available diesel liquid fuel. The experiments utilized available diesel fuel that has met its necessary requirements. Measurment of the parameters were registered for constant rational speed $\mathrm{n}=2200 \mathrm{rpm}$. The speed was maintained at a constant, with automaticaly controlled brake.

In the case of supplying with the Diesel liquid fuel there were changed the dose of Diesel liquid fue. The other constant parameter were the following:

- injection pressure $60 \mathrm{MPa}$

- angle of injection $15^{\circ}$ BTDC.

- Output measured:

- the engine load $(\mathrm{Nm})$;

- the share of ingredients in exhaust gas: $\mathrm{O} 2(\%), \mathrm{CO} 2(\%), \mathrm{CO}(\mathrm{ppm}), \mathrm{HC}(\%), \mathrm{NOx}(\mathrm{ppm})$.

In the case of supplying with the bio-gas there was a changing the amount of gas- mixture. The other constant parameter were the following:

- dose of liquid fuel - $2.3 \mathrm{~mm} 3 / 1$ injection;

- injection pressure $60 \mathrm{MPa}$;

- angle of injection $15^{\circ} \mathrm{BTDC}$;

- output measured:

- the engine load $(\mathrm{Nm})$

- the share of ingredients in exhaust gas: $\mathrm{O} 2(\%), \mathrm{CO} 2(\%), \mathrm{CO}(\mathrm{ppm}), \mathrm{HC}(\%), \mathrm{NOx}(\mathrm{ppm})$.

The results of the tests are ilustrated in Figure 2-6. The presented results suggest that emissions of non-toxic compounds such as $\mathrm{O}_{2}$ and $\mathrm{CO}_{2}$ doesn't depend on the kind of used fuel regardless of diesel liquid fuel or gas -mixture. The share of the of toxic ingredients( $\mathrm{CO}$ and $\mathrm{HC})$ in the exhaust gas in the case of supplying with the gas mixture significantly increased. In both casesof fuel types the higher the torque,the lower were theemission ingredients. These difference are caused by various burning process. The obtained results confirms the results described by other researchers $[3,4,5,6]$. The increase in emissions of these compounds is caused by the different placement of fuel mixture in the engine chamber.

In the case of the liquid fuel supply injected into the combustion chamber fuel dose is burned in the limited area smaller than the space of the chamber. In the second case, the chamber is entirely fulfilled with a homogenous mixture of methane and air. Injection of a small dose of fuel initiates local process of burning spreading with various velocity on the whole space of the chamber. The velocity of spreading depends on the share of the flammable gas in the mixture.

For the load of engine on low level the provided gas mixture contains relatively small amount of methan. Front of flame in such case moves slower. This way the entire burning cycle last longer. In extreme situation it is was completed in 
working cycle and the part of gas remainded did not react. During the experiment for the higher loads there was observed significant increase of the $\mathrm{NO}_{\mathrm{x}}$ in the exhaust gas. It is directly connected with the higher teperatures in the chamber achieved as a result of higher temperatures burning of methane. Concerning the course of the overall efficiency as a function of the load, there was observed similar shape of the chart which depicts it for both ways of supplying - liquid fuel/gas mixture, however the location of the curve for the second case is moved down.

Analyzing the changes in the overall efficiency of the engine can be seen that at low loads in the event of engine power, methane had a reduction in overall efficiency, due to the deterioratew of the combustion mixture (lean-burn). At higher loads, the efficiency of an engine fed by methane is only slightly less than that of the liquid fuel supply.

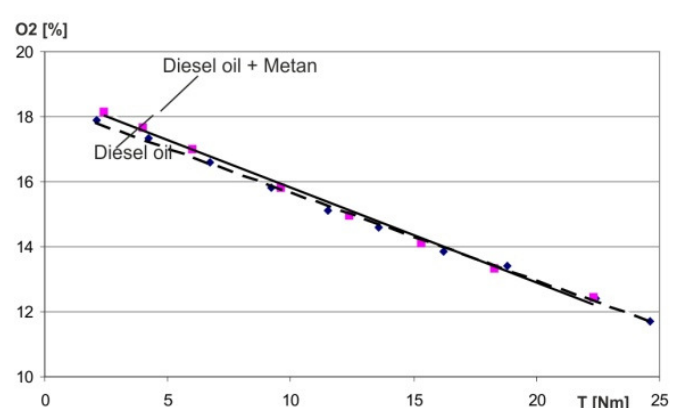

Fig. 4. Exhaust emission $\mathrm{O}_{2}$ in the function of load engine

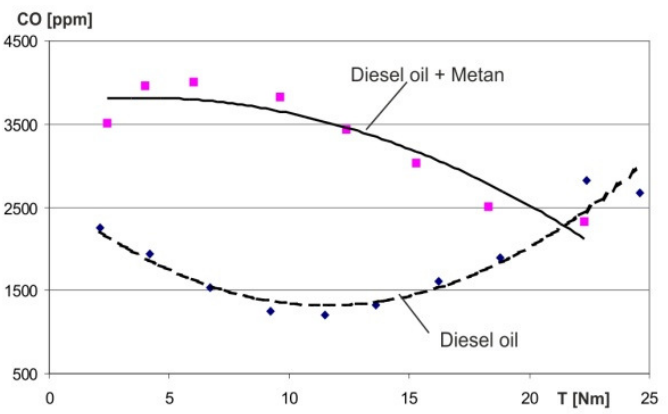

Fig. 6. Exhaust emission $\mathrm{CO}$ in the function of load engine

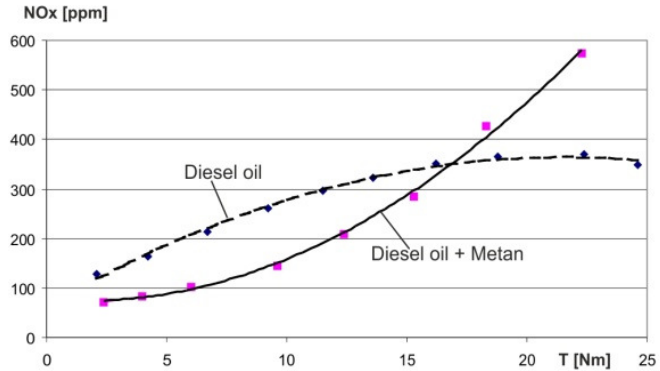

Fig. 8. Exhaust emission $\mathrm{HC}$ in the function of load engine

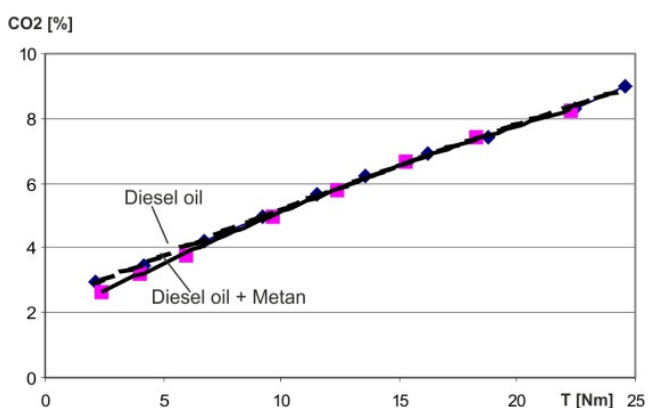

Fig. 5. Exhaust emission $\mathrm{CO}_{2}$ in the function of load engine

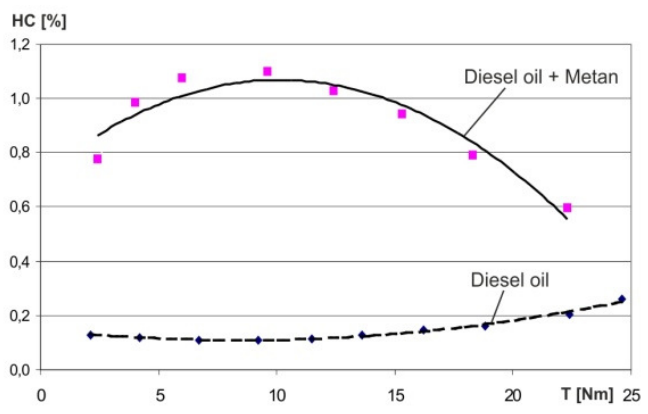

Fig. 7. Exhaust emission $\mathrm{HC}$ in the function of load engine

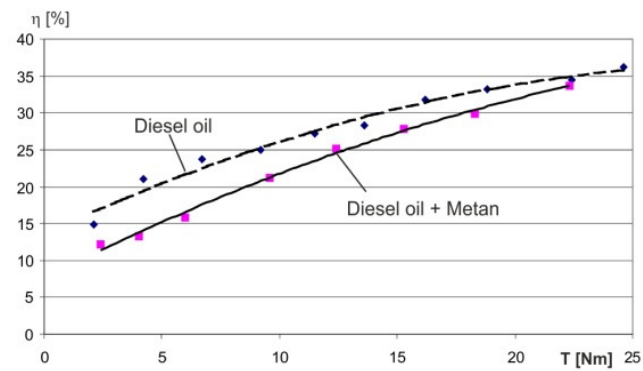

Fig. 9. Overall efficiency of the engine in the function of load

\section{Summary}

The results of the experiment confirm the effectiveness of diesel engine supplied with bio-gas. In spite of its lower overall efficiency in case of feeding it with methane rather than liquid fuel this efficiency is still significantly more beneficial than in SI engines. However, some parameters of the burning process such as: $\mathrm{CO}, \mathrm{HC}, \mathrm{NO}_{\mathrm{x}}$, are not improved, the tendency to change relations between resources of fossil fuels and renewable sources confirm necessity of developing solution - "dieselbiofuel". Increased level of $\mathrm{CO}, \mathrm{HC}$ is currently successfully reduced with catalyzer. As far as $\mathrm{NO}_{\mathrm{x}}$ are concerned, there could be considered exploitation of CI engine in selected scope of loads. Additionally in the further works there are planned precise researches to determine effect of exhaust gas recirculation on decrease of $\mathrm{NO}_{\mathrm{x}}$ emission. The contents of methane in bio-gas in numerous biofarms is on the level much less than $90 \%$, it will be taking into account as well. 


\section{Acknowledgements}

The paper was prepared as part of research project no. N N509 573039 funded by the National Science Centre.

\section{References}

[1] Azimov, U.; Tomita. E.; Kawahara, N.; Dol, S. S. 2012. Combustion characteristics of syngas and natural gas in micro-pilot ignited dual-fuel engine, World Academy of Science, Engineering and Technology 72: 1618-1625.

[2] Kneba, Z.; Śmieja, M. 2010. The automation of test stand for engine cooling system testing, Solid State Phenomena 164: 61-66. http://dx.doi.org/10.4028/www.scientific.net/SSP.164.61

[3] Korakianitis, T.; Namasivayam, A. M.; Crookes, R. J. 2011. Diesel and rapeseed methyl ester (RME) pilot fuels for hydrogen and natural gas dual-fuel combustion in compression-ignition engines, Fuel 90: 2384-2395. http://dx.doi.org/10.1016/j.fuel.2011.03.005

[4] Makareviciene, V.; Sendzikiene, E.; Pukalskas, S.; Rimkus, A.; Vegneris, R. 2013. Performance and emission characteristics of biogas used in diesel engine operation, Energy Conversion and Management 75: 224-233. http://dx.doi.org/10.1016/j.enconman.2013.06.012

[5] Ray, N. H. S.; Mohanty, M. K.; Mohanty, R. C. 2013. Biogas as alternate fuel in diesel engines: A literature review, Journal of Mechanical and Civil Engineering 9(1): 23-28. http://dx.doi.org/10.9790/1684-0912328

[6] Ray, N. H. S.; Mohanty, M. K.; Mohanty, R. C. 2013. A Study on application of biogas as fuel in compression ignition engines, International Journal of Innovations in Engineering and Technology (IJIET) 3(1): 239-245.

[7] Piętak, A.; Wierzbicki, S.; Duda, K. 2012. Possibility of automation of a mobile biodiesel production plant, Solid State Phenomena. Mechatronic Systems, Mechanics and Materials 180: 76-88.

[8] Szwaja, S.; Tutak, W.; Grab-Rogaliński, K.; Jamrozik, A.; Kociszewski, A. 2012. Selected combustion parameters of biogas at elevated pressuretemperature conditions, Combustion engines 1(148): 40-47.

[9] Wierzbicki, S.; Śmieja, M. 2014. Visualization of the parameters and changes of signals controlling the operation of common rail injectors, Diffusion and Defect Data Pt.B: Solid State Phenomena 210: 136-141. http://dx.doi.org/10.4028/www.scientific.net/SSP.210.136

[10] Biogas barometer. BAROMETRE BIOGAZ - EUROBSERV'ER - NOVEMBRE 2001, http://www.eurobserv-er.org/pdf/baro200b.pdf 